19 Revue d'histoire du XIXe siècle

Société d'histoire de la révolution de 1848 et des

révolutions du XIXe siècle

29 | 2004

Varia

\title{
Charles Esdaile, The Peninsular War. A New History, New York, Palgrave Macmillan, 2003, 587 p.
}

\section{Richard Hocquellet}

\section{OpenEdition}

\section{Journals}

Édition électronique

URL : http://journals.openedition.org/rh19/707

DOI : 10.4000/rh19.707

ISSN : $1777-5329$

Éditeur

La Société de 1848

\section{Édition imprimée}

Date de publication : 1 décembre 2004

Pagination : 177-179

ISSN : 1265-1354

Référence électronique

Richard Hocquellet, « Charles Esdaile, The Peninsular War. A New History, New York, Palgrave

Macmillan, 2003, 587 p. », Revue d'histoire du XIXe siècle [En ligne], 29 | 2004, mis en ligne le 29 juin

2005, consulté le 21 décembre 2020. URL : http://journals.openedition.org/rh19/707 ; DOI : https:// doi.org/10.4000/rh19.707

Ce document a été généré automatiquement le 21 décembre 2020.

Tous droits réservés 


\title{
Charles Esdaile, The Peninsular War. A New History, New York, Palgrave Macmillan, 2003, 587 p.
}

\author{
Richard Hocquellet
}

1 Charles Esdaile, historien d'outre-Manche spécialiste des guerres napoléoniennes et plus particulièrement du conflit franco-britannique dans le cadre de la péninsule ibérique, s'est illustré ces dernières années par le renouvellement qu'il propose de l'étude du phénomène de la guérilla à la frontière du social et du militaire. La guérilla n'est pas tant une tactique de David contre Goliath qu'un mode de lutte utilisant à la fois les ressorts de mobilisation de populations fortement structurées par des solidarités locales et verticales et les pratiques de transgression de la loi, quand surgit la conscience d'une menace de l'équilibre de la communauté. Le dernier ouvrage d'Esdaile, paru aux États-Unis en 2003, montre une nouvelle fois sa volonté de ne pas considérer l'histoire des guerres sous le seul angle militaire. The Peninsular War étudie le conflit au Portugal et en Espagne entre 1808 et 1814 dans ses dimensions stratégiques et tactiques, bien sûr, mais aussi politiques et sociales. L'ambition est vaste, le livre est à sa mesure : plus de 500 pages de texte dense, hors notes et bibliographie, foisonnant d'informations, écrit dans un style alliant rigueur et élégance. L'insertion de reproductions de gravures et de tableaux d'époque complète l'intention d'en faire un ouvrage de référence.

2 La succession des chapitres reprend les lieux emblématiques du conflit qui leur donnent leur titre : Bailén, Cadix, Somosierra, Vitoria... Respirations dans le flux des informations ou goût pour une écriture romanesque, chacun s'ouvre par une courte évocation plus littéraire des moments les plus forts. La démarche historiographique mêle ensuite les genres. À côté du récit précis des batailles (position, forces en présence, mouvements, bilan), des développements sur la situation locale (réalités socio-économiques, environnement géographique, implication des populations) et sur les enjeux de pouvoir (rivalités entre autorités, intérêts des différents protagonistes, motivation des principales figures) font apparaître la complexité de cette guerre. On 
pourrait dire histoire totale pour une guerre totale. La volonté de globalisation n'est pourtant pas si aboutie que l'on pourrait le souhaiter suite à l'enthousiasme que suscite la lecture de la préface de l'auteur. En effet, peut-être en raison du choix du découpage chronologique suivant les différentes opérations militaires, l'accent est porté principalement sur l'affrontement armé et les autres aspects semblent venir en compléments, comme une contextualisation de la guerre.

3 La composante politique, du côté espagnol, portugais et afrancesado (ceux qui collaborent avec Joseph Bonaparte) est essentielle pour comprendre aussi bien la durée que le déroulement du conflit. La diplomatie anglaise et le comportement de Napoléon $\mathrm{I}^{\mathrm{er}}$, très étudiés de manière convaincante, n'expliquent pas à eux seuls pourquoi il faut six années pour en terminer. Le point de vue espagnol est particulièrement nécessaire à prendre en compte et Charles Esdaile le sait bien, qui s'y réfère chaque fois que besoin. Pourtant, on peut regretter que certains clichés concernant le gouvernement patriote et les députés libéraux des Cortes de Cadix soient repris tels quels sans être questionnés, alors que d'autres clichés font l'objet d'une révision critique opportune et pertinente à d'autres moments de l'ouvrage.

4 Il n'en reste pas moins deux apports fondamentaux: d'une part, la richesse documentaire de la description des batailles, des sièges, des déplacements des troupes lors des différentes campagnes (une série de 22 plans des principales batailles figurent en hors texte) ainsi que leurs effets sur les populations locales; d'autre part, la vision géographique globale du conflit que seul, peut-être, pouvait développer un historien britannique. En effet, en ne séparant pas guerre du Portugal et guerre d'Espagne, les Anglais ont nommé le conflit « guerre de la Péninsule ». Autre intérêt, lié à la spécificité de l'auteur, le point de vue interne britannique est régulièrement présenté : débats au sein du gouvernement sur les choix stratégiques, intérêts coloniaux et commerciaux, état de l'opinion. En raison du régime monarchique parlementaire, les lignes politiques sont plus complexes et la conduite de la guerre n'est pas aussi liée au comportement, encore moins à la personnalité, du chef du gouvernement que pour la France impériale.

Et pourtant, Charles Esdaile, comme tous les historiens qui l'ont précédé, avoue les difficultés à débrouiller l'attitude, les choix de Napoléon $\mathrm{I}^{\mathrm{er}}$, principalement au début de la guerre. L'occupation du Portugal à l'automne 1807 est, certes, rapide mais a coûté cher en hommes qui ont dû faire de longues marches forcées. Sur place, à Lisbonne, la population coopère peu. Le prince régent et la famille royale se sont réfugiés au Brésil, rendant impossible toute négociation. Le sort que l'Empereur entend réserver à l'Espagne, officiellement alliée de la France, n'est pas clair dans les premiers mois de 1808. Il semble évident qu'il garde plusieurs options ouvertes. L'intervention directe dans les affaires de la monarchie hispanique est provoquée par la crise interne dans la famille royale: abdication de Charles IV à la suite d'une émeute à Aranjuez et avènement de son fils Ferdinand. On sait, et Esdaile le rappelle à juste titre, que le soulèvement patriotique, point de départ de la guerre sur le sol espagnol, est déclenché par les nouvelles des abdications collectives des Bourbons d'Espagne en faveur de Napoléon début mai 1808 (et non par le stationnement des troupes, ni par la répression de l'émeute madrilène du 2 mai).

6 La présentation des différentes étapes du conflit renvoie à la variété des forces en présence et à la multiplicité des facteurs interférant dans les événements. On retiendra ici quelques points forts qui font débat ou qui correspondent à des éclairages intéressants. Si les premières victoires des patriotes durant l'été 1808 (Bailén, 19 juillet) 
s'expliquent avant tout par un effet de surprise - aussi bien en termes tactiques qu'en termes de mobilisation inattendue de la population-, leurs défaites pendant la campagne de l'automne, menée par Napoléon en personne, sont dues à la supériorité structurelle globale de l'armée impériale. L'intervention des Britanniques, qui ont pris pied au Portugal, prive les Français d'une victoire rapide et ce malgré la retraite désastreuse du général Moore en Galice. C'est à partir de l'hiver 1808 qu'apparaît véritablement le phénomène de la guérilla dont le rôle stratégique reste minime. Elle contredit certes l'avantage théorique des Français qui tiennent la majeure partie des provinces, mais son caractère local et improvisé empêche de transformer ses succès ponctuels en véritable dynamique de libération du territoire. Toute la question est l'alliance entre les patriotes espagnols et le corps expéditionnaire britannique associé à l'armée portugaise reconstituée. L'auteur insiste beaucoup sur les relations difficiles entre les différents gouvernements patriotes et le commandant en chef anglais, Arthur Wellesley, duc de Wellington. Il semble que la durée de la guerre soit à mettre sur le compte de ces difficultés à s'accorder, d'un côté sur les méthodes, de l'autre sur les priorités. En arrière plan de ces dissensions, longuement et précisément détaillées sous leur aspect militaire et de querelles personnelles, se profile la question politique: Wellington est opposé au processus révolutionnaire en cours. Après l'ouverture des Cortes de Cadix, assemblée qui proclame la souveraineté nationale (1810) puis une constitution libérale (1812), l'entente est encore plus difficile. De plus, les antagonismes coloniaux restent présents, d'autant plus après les premières insurrections autonomistes de l'été 1810 en Amérique espagnole. Cet aspect aurait certainement mérité d'être traité de façon plus poussée car il permet de comprendre la méfiance des patriotes vis-à-vis de la Grande-Bretagne. En particulier, lorsque l'avantage passe dans le camp "allié » (les Anglo-Portugais et les Espagnols) durant l'été 1812, les négociations entre les Cortes et Wellington au sujet d'un commandement unique retardent l'issue victorieuse du conflit. L'accord enfin trouvé en janvier 1813, leur permet de lancer les campagnes finales pour d'abord mettre fin au régime de Joseph Bonaparte puis de repousser les troupes impériales hors de la péninsule (bataille de Vitoria) et même de les poursuivre dans le Sud-Ouest de la France, participant ainsi à la chute de l'Empire envahi par les autres coalisés au Nord.

7 Le livre se termine par une interrogation sur le rôle de cette guerre dans la fin de l'aventure napoléonienne, pour noter que l'historiographie semble moins affirmative que ce que Napoléon lui-même a pu relater aux témoins de son exil à Saint Hélène. Il considérait que sa principale erreur avait été de vouloir dominer la péninsule. Les historiens de la période ont tendance à attacher plus d'importance à la campagne de Russie. Ce qui est certain est l'impact du conflit sur l'histoire ultérieure immédiate du Portugal et de l'Espagne: d'un point de vue politique et social, il est le véritable point de départ de la transition de l'Ancien Régime à la modernité. 